\author{
Scientific Electronic Archives \\ Issue ID: Sci. Elec. Arch. Vol. 14 (8) \\ August 2021 \\ DOI: http://dx.doi.org/10.36560/14820211303 \\ Article link: https://sea.ufr.edu.br/SEA/article/view/1303
}

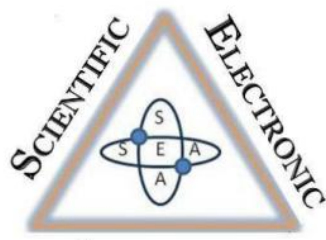

ArChives

ISSN 2316-9281

\title{
Avaliação da densidade populacional de perfilhos dos capins Marandu e Piatã submetidos à adubação com cama de frango e esterco de bovinos confinados
}

\section{Evaluation of the population density of tillers from Marandu and Piatã grasses submitted to fertilization with chicken litter and confined cattle manure}

\author{
Verônica Silveira Vasconcelos Luz \\ Secitec - MT \\ veronicasluz@hotmail.com \\ Marcelo Barcelo Gomes \\ Instituto Federal de Mato Grosso do Sul - Campus de Naviraí \\ Josilene da Silva Trindade \\ Centro Universitário do Vale do Araguaia \\ Waldivina Eterna Silveira Luz \\ Médica Veterinária Autônoma \\ Valeria Lima da Silva \\ Universidade Federal de Goiás
}

Resumo. Objetivou-se avaliar densidade populacional de perfilhos dos capins Brachiaria brizantha cv. Marandu e cv. Piatã, submetidos à adubação com cama de frango e esterco de bovinos confinados. $O$ experimento foi conduzido no campo experimental das Faculdades Unidas do Vale do Araguaia, em delineamento em blocos casualizados em esquema fatorial $2 \times 2 \times 2$, sendo Marandu e Piatã, adubados com cama de frango e esterco bovino e doses 0 e 2,5 t.ha ${ }^{-1}$, com quatro repetições. Quando as metas de altura de 25 (Marandu) e 30 (Piatã) cm foram atingidas realizou- se cortes, em seguida realizada amostragem da densidade populacional de perfilhos, contando-se do total de perfilhos dentro da armação de pvc de $1,00 \times 0,25 \mathrm{~m}$. As cultivares utilizadas apresentaram variação na densidade populacional de perfilhos. A adubação orgânica apresentou efeito sobre o intervalo de corte . Recomenda-se a adubação com cama de frango sobre as pastagens para proporcionar a diminuição do intervalo de pastejo.

Palavras-chave: adubação orgânica, corte, forragem, perfilhamento.

\begin{abstract}
Aimed to evaluate tiller density of grasses Brachiaria brizantha cv. Marandu and cv. Piata undergoing fertilization with poultry litter and feedlot manure. The experiment was conducted in the experimental field of the United Colleges of the Araguaia Valley, in a randomized block design in a factorial design $2 \times 2 \times 2$, being Marandu and Piata fertilized with poultry litter and cattle manure and doses 0 and $2.5 \mathrm{t}$ ha- 1 with four replications. When the height of goals 25 (Marandu) and 30 (Piata) $\mathrm{cm}$ were hit realizou- if cuts then held sampling tiller density, counting the total number of tillers within the PVC frame of $1.00 \times 0.25 \mathrm{~m}$. The cultivars showed variation in tiller density. The organic fertilization showed effect on the cutting interval .Recomenda to fertilization with poultry litter on pastures to provide the reduction of grazing interval.
\end{abstract}

Keywords: organic fertilization, court, fodder, tillering.

\section{Introdução}

O cerrado representa $23 \%$ do total de áreas do bioma brasileiro, possui características de solo com topografia, estrutura, e textura desejável para a produção animal. Porém, a estacionalidade de chuvas, juntamente com a ocorrência de veranicos, e baixa fertilidade do solo, impedem o desenvolvimento de raízes, exigindo assim plantas adaptáveis, onde as forrageiras do gênero 
Brachiaria se encaixa em um padrão satisfatório nesse requisito (RODRIGUES, 2014).

De acordo com Azevedo Junior (2011), a Brachiaria brizantha é uma espécie difundida mundialmente, descrita como uma planta perene, cespitosa, muito robusta, lâminas foliares lineares e lanceoladas, rizomas curtos e encurvados. É uma planta que possui boa adaptação aos solos do cerrado respondendo bem à adubação fosfatada e sendo resistente a cigarrinha. Suas cultivares Marandu, Xaraés e Piatã, são forrageiras que atendem bem a necessidade de produção de bovinos e a diversificação de pastagens. Das três cultivares a Brachiaria brizantha cv. Marandu foi à de início, destaque dos cultivares, logo depois em 2006 a EMBRAPA lançou o cultivar Piatã, sendo uma forragem mais produtiva e mais resistente à seca. Comparando-se o cultivar Marandu e Piatã, a produção é $80 \%$ na água e $20 \%$ na seca e $70 \%$ na água e 30\% na seca, respectivamente.

As forrageiras são formadas por um conjunto de perfilhos, sendo os mesmos a unidade molecular de crescimento dessas plantas. Sendo assim, os perfilhos formam a base estrutural da planta e possui seu próprio sistema radicular. Dessa forma, essas características são importantes tanto para a eficiência de produção da forragem quanto para o desempenho dos animais que a consomem (FIALHO, et al., 2012) Em pastagens de gramíneas a unidade primária de crescimento é o perfilho, sendo que uma pastagem é considerada uma população de perfilhos (SBRISSIA, 2000).

A densidade populacional de perfilhos é uma característica intrínseca para a produção de forragem, pois através dela é possível observar 0 desenvolvimento da planta, proporcionando o uso racional e controlado da mesma. Sendo assim esse método permite o uso controlado e técnicas de manejo idealizadas com base nos dados coletados da forragem, através da avaliação de densidade populacional (FAGUNDES, et al., 2005). Portanto, através dessas avaliações é possível observar a dinâmica, morte e aparecimento de perfilhos, permitindo observar a flexibilidade de ajuste da planta a diferentes regimes de desfolhação (FIALHO, et al., 2012).

De certa forma o objetivo principal do manejo do pastejo é a colheita da maior proporção de folhas em relação ao colmo e material morto, sem prejudicar o processo de rebrotação seguinte. Sendo assim, é necessário compreender os processos de crescimento e desenvolvimento da forragem, sendo que, estudos embasados na relação entre sobrevivência e aparecimento de perfilhos, bem como as relações de morte, dependente de densidade populacional e tornam-se de grande importância (SANTOS, 2014). Nesse processo de manejo para a otimização da produção a adubação é uma etapa necessária para se obter resultados positivos.

Segundo Portugal et al., (2009), os insumos tipo resíduo orgânico são considerados de baixo custo e de alta rentabilidade para a agropecuária. A cama de frango é uma excelente fonte de nutriente, no qual é composta de nitrogênio. Pesquisas de Teles (2013), revelam que a pastagem é o único sistema de produção agrícola que tem restrição a aplicação da cama de frango devendo ser respeitada a legislação do Ministério da Agricultura, Pecuária e Abastecimento - MAPA, através da Instrução Normativa N. 25 de 23, de julho de 2009, a qual descreve que a cama de aves só deve ter seu uso permitido quando realizada a incorporação ao solo e pastoreio somente após 40 dias.

No processo de criação em confinamento de bovinos, o acúmulo de dejetos promove uma alta quantidade de resíduo orgânico, que consequentemente possibilita a proliferação de moscas e mosquitos, além de causar poluição prejudicando o meio ambiente. Portanto, o esterco é composto pela parte sólida dos dejetos, incluindo fezes, cama e ração com teores de $18 \%$ a $40 \%$ de matéria seca. Sendo assim, pode-se utilizar o esterco de confinamento como adubo orgânico, sendo uma maneira prática e econômica utilizada como fertilização (MANSO e FERREIRA, 2007).

A Associação Nacional para Difusão de Adubos (ANDA) e o Sindicato da Indústria de Adubos e Corretivos Agrícola, declararam que a produção de adubos nitrogenados no Brasil em 2010 era de apenas $27 \%$, de um total, aproximadamente, de 2,8 milhões de toneladas consumidas, enquanto os fosfatados, somente $49 \%$ de 3,7 milhões de toneladas consumidas são produzidos, sendo que os adubos potássicos apresentam a situação mais problemática, tendo em vista que, somente $10 \%$, de cerca de 4,2 milhões de toneladas consumidas são originadas da produção interna. Sendo assim, a utilização de dejetos de animais na substituição dos fertilizantes químicos vem se tornando uma alternativa, visto que, fontes orgânicas de nutrientes podem substituir fontes químicas de NPK. Desse modo, a utilização dos dejetos de aviários e confinamento pode diminuir 0 custo de produção de forragem, melhorando 0 manejo e o destino final desses resíduos, aproveitando-os de forma sustentável (TELES, 2013).

Objetivou-se com este trabalho avaliar a densidade populacional de perfilhos do capim Brachiaria brizantha cv. Marandu e cv. Piatã, submetidos à adubação orgânica com cama de frango e esterco de baia de confinamento.

\section{Métodos}

O experimento foi conduzido entre 0 período de outubro de 2014 à março de 2015, no campo experimental das Faculdades Unidas do Vale do Araguaia -UNIVAR, no município de Barra do Garças no Estado de Mato Grosso, localizada nas coordenadas geográficas: latitudes $15^{\circ} 53^{\prime} 26^{\prime}$ $\mathrm{S}$ e longitude $52^{\circ} 16^{\prime} 44^{\prime} \mathrm{W}$ e altitude $344 \mathrm{~m}$ (Figura 3). O clima da região, de acordo com a classificação de Köppen é do tipo AW, clima quente e úmido) com duas estações bem definidas, verão chuvoso (outubro a março) e inverno seco (abril a setembro). 
Onde a média de precipitação anual foi de 1578,9 $\mathrm{mm}$ e a temperatura anual foi de $25,6^{\circ} \mathrm{C}$.

Para a implantação do experimento houve a delimitação da área e foram coletadas amostras de solo da área experimental na profundidade de 0-20 $\mathrm{cm}$, as quais foram submetidas à análise química $\mathrm{e}$ física obtendo-se os seguintes resultados: $\mathrm{pH}$ $\left(\mathrm{CaCl}_{2}\right): 4,9 ; \mathrm{Ca}\left(\mathrm{cmol}_{\mathrm{c}} \cdot \mathrm{dm}^{-3}\right): 4,33 ; \mathrm{Mg}\left(\mathrm{cmol}_{\mathrm{c}} \cdot \mathrm{dm}^{-3}\right)$ : 1,15; Al $\left(\mathrm{cmol}_{\mathrm{c}} \cdot \mathrm{dm}^{-3}\right): 0,12 ; \mathrm{H}+\mathrm{Al}\left(\mathrm{cmol}_{\mathrm{c}} \cdot \mathrm{dm}^{-3}\right): 5,0 ; \mathrm{K}$ $\left(\mathrm{cmol}_{\mathrm{c}} \cdot \mathrm{dm}^{-3}\right): 0,42 ; \mathrm{P}\left(\mathrm{mg} \cdot \mathrm{dm}^{-3}\right): 3,4 ; \mathrm{S}\left(\mathrm{mg}^{-3} \mathrm{dm}^{-3}\right)$ : 3,4; B $\left(\mathrm{mg}^{-3} \mathrm{dm}^{-3}\right): 0,05 ; \mathrm{Cu}\left(\mathrm{mg} \cdot \mathrm{dm}^{-3}\right): 1,2 ; \mathrm{Fe}$ $\left(\mathrm{mg} \cdot \mathrm{dm}^{-3}\right): 184 ; \mathrm{Mn}\left(\mathrm{mg} \cdot \mathrm{dm}^{-3}\right): 60,8 ; \mathrm{Zn}\left(\mathrm{mg}^{-3} \mathrm{dm}^{-3}\right):$ 3,6; Matéria Orgânica $\left(\mathrm{g} \cdot \mathrm{dm}^{-3}\right): 31,3$; Capacidade de Troca de Cátions $\left(\mathrm{cmol}_{\mathrm{c}} \cdot \mathrm{dm}^{-3}\right): 10,9$; Saturação por bases: $54,1 \%$; Argila $\left(\mathrm{g} \cdot \mathrm{dm}^{-3}\right)$ 345; Silte $\left(\mathrm{g} \cdot \mathrm{dm}^{-3}\right)$ 100; Areia $\left(\mathrm{g} \cdot \mathrm{dm}^{-3}\right)$ 555. Com os dados obtidos foi realizada a determinação da necessidade de correção de acidez, elevando a saturação por bases para $60 \%$ e adubação corretiva $\left(643 \mathrm{~kg} \cdot \mathrm{ha}^{-1}\right.$ de calcário) de fósforo (175 kg.ha-1 de Superfosfato Simples), e micronutrientes (50 kg.ha ${ }^{-1}$ ).

As sementes dos capins Brachiaria brizantha cv. Marandu e Brachiaria brizantha cv. Piatã foram obtidas através de empresas locais, na qual avaliou-se a pureza e germinação e com estes dados determinou-se o valor cultural de $60 \%$ para determinar a taxa de semeadura utilizando 500 Pontos de Valor Cultural por hectare, os quais representaram a quantidade de $8,33 \mathrm{~kg} \cdot \mathrm{ha}^{-1}$.

Os tratamentos corresponderam à combinação de dois capins, Marandu e Piatã, com duas fontes de adubação orgânica, sendo a cama de frango e o esterco bovino de confinamento e duas doses de adubação orgânica, 0 e 2,5 t.ha ${ }^{-1}$ arranjados em fatorial $2 \times 2 \times 2$, totalizando oito tratamentos distribuídos em delineamento de blocos casualisados com quatro repetições, obtendo-se 32 unidades experimentais (8 tratamentos $\times 4$ repetições). Cada unidade experimental foi composta por nove metros quadrados $(3 \times 3 \mathrm{~m})$, totalizando uma área experimental de $288 \mathrm{~m}^{2}$.

Realizou- se a análise do abubo de cama de frango, onde se obteve: $83,56 \%$ de Matéria Seca, $30,48 \%$ de Matéria Mineral, 2,89\% de Extrato Etéreo\% e $21,83 \%$ de Proteína Bruta, a qual foi utilizada para determinar a quantidade de nitrogênio aplicado, que correspondeu a $87,25 \mathrm{~kg} \cdot \mathrm{ha}^{-1}$.

Após 45 dias da germinação e emergência das plântulas foi realizado um corte de uniformização a $15 \mathrm{~cm}$ do solo com auxílio de uma cortadora e posteriormente a adubação com a cama de frango e o esterco bovino de confinamento.

Após o corte de uniformização e adubação, realizou-se o monitoramento da rebrota das parcelas medindo-se a altura dos capins utilizando uma folha de transparência como referência (FAGUNDES et al., 1999) utilizando um "sward stick" (BARTHRAM, 1985), com os quais foram realizadas dez leituras em cada parcela experimental. Em cada ponto, dos quatro lados da transparência, registrou - se o maior e o menor valor de altura, obtendo, portanto, a altura média do ponto. As metas de altura de corte foram de $25 \mathrm{~cm}$ para a Brachiaria brizantha cv. Marandu e de $30 \mathrm{~cm}$ para a Brachiaria brizantha cv. Piatã, deixando um resíduo de $15 \mathrm{~cm}$.

Assim que as metas de altura de corte iam sendo atingidas foi feito o corte da parcela e em seguida realizada a amostragem da densidade populacional de perfilhos, por meio da contagem do total de perfilhos contidos no interior de uma armação de pvc de $1,00 \times 0,25 \mathrm{~m}$, a qual foi lançada aleatoriamente dentro da parcela no momento da amostragem

A análise de variância dos dados foi realizada para detectar os efeitos das causas de variação (adubação orgânica, espécies e interações entre elas) e a comparação das médias foi realizada por meio do teste de Tukey a um nível de significância de $5 \%$.

\section{Resultados e discussão}

Houve diferença na densidade populacional de perfilhos somente para cultivares $(P<0,001)$. Já para as adubações e as variáveis do intervalo de corte e número de corte não houve diferença estatística (Tabela 1).

Tabela 1. Resumo da análise de variância das variáveis avaliadas em função da adubação orgânica sobre os capins Marandu e Piatã.

\begin{tabular}{cccc}
\hline $\begin{array}{c}\text { Fonte de } \\
\text { avaliação }\end{array}$ & $\begin{array}{c}\text { DPP } \\
\left.\text { (perfilhos } / \mathrm{m}^{2}\right)\end{array}$ & $\begin{array}{c}\text { Intervalo de } \\
\text { corte } \\
\text { (dias) }\end{array}$ & $\begin{array}{c}\text { Número de } \\
\text { cortes }\end{array}$ \\
\hline Cultivar & $\mathrm{P}<0,001$ & $\mathrm{P}=0,4793$ & $\mathrm{P}=0,3522$ \\
Adubo & $\mathrm{P}=0,1492$ & $\mathrm{P}=0,0112$ & $\mathrm{P}=0,2577$ \\
$\mathrm{CV}(\%)^{1}$ & 14,96 & 9,45 & 16,12 \\
\hline \multicolumn{4}{c}{ CV: coeficiente de variação } \\
\end{tabular}

Houve efeito das cultivares sobre a densidade populacional de perfilhos, sendo que a Brachiaria brizantha cultivar Marandu apresentou o maior valor (Tabela 2).

Tabela 2. Densidade populacional de perfilhos -DPP dos capins Marandu e Piatã submetidos à adubação com cama de frango e esterco de bovinos confinados.

\begin{tabular}{ccc}
\hline Cultivar & DPP $\left(\right.$ perfilhos $\left./ \mathrm{m}^{2}\right)$ & EPM \\
\hline Marandu & $688 \mathrm{a}$ & 21,94 \\
Piatã & $485 \mathrm{~b}$ & 21,94
\end{tabular}

EPM : erro padrão da média. Médias seguidas de letra diferente minúscula na coluna diferem entre si $(P>0,005)$ pelo teste de Tukey.

De acordo com o estudo de Santos (2014), os maiores valores para a densidade populacional de pefilhos foram observados nos pastos manejados com $10 \mathrm{~cm}$ de altura, com queda a partir da altura de $15 \mathrm{~cm}$ e uma tendência de estabilização a partir da altura de $20 \mathrm{~cm}$. Já no presente trabalho a menor altura do Marandu, 25 $\mathrm{cm}$, colaborou para o maior número de perfilhos, o que acabou proporcionando maior cobertura do solo. O menor número de perfilhos da cultivar Piatã pode ser explicado pelo fato da planta apresentar suas relações de estrutura adequada a partir de 30 $\mathrm{cm}$ de altura. Desta forma, há perfilhos maiores em relação à cultivar Marandu que, por apresentar 
menor altura apresentou mais perfilhos de tamanhos menores. Para Sbrissia e Silva (2008), os valores de densidade populacional de perfilhos corroboram com vários resultados disponíveis na literatura, que indicam decréscimo na população de perfilhos à medida que os pastos são mantidos mais altos. Essa competição entre perfilhos ocorre particularmente por luz, ou seja, a baixa intensidade luminosa na base do relvado é, reconhecidamente, um dos principais fatores que interferem na capacidade de perfilhamento de pastos mantidos mais altos.

De acordo com Santos (2014), a quantidade de perfilhos também sofre alterações em relação a limitação de recursos causada pelos próprios perfilhos. Sendo que, quando a densidade populacional de perifilhos (DPP) está muito baixa existem recursos para o crescimento e sobrevivência, ou seja, com o aumento em número, começa uma competição entre perfilhos pelos mesmos recursos, aumentando a taxa de mortalidade de perfilhos ou diminuindo a densidade de plantas. Porém, a densidade populacional sozinha não é indicativo de produtividade do pasto, pois pode haver situações de alta densidade populacional de perfilhos, porém baixa taxa de sobrevivência de perfilhos, o que indica baixa estabilidade do pasto ou o inverso, ou seja, pastos com poucos perfilhos na área.

Para Sbrissia (2000), o processo de competição entre os perfilhos pode ser interpretado como um auto-desbaste que ocorre pela competição de luz, ou seja, as plantas pequenas que morrem e a morte de folhas ocorre quando elas não mantem suas folhas o alto suficiente no relvado para manter o balanço positivo de carbono.

Para a adubação não houve efeito significativo dos adubos utilizados para as análises feitas de densidade populacional de perfilhos (Tabela 3).

Tabela 3. Densidade populacional de perfilhos em parcelas de Capim Marandu e Piatã submetidos à adubação com cama de frango e esterco de bovinos confinados.

\begin{tabular}{ccc}
\hline Adubo & DPP $\left(\right.$ perfilho $\left./ \mathrm{m}^{2}\right)$ & EPM \\
\hline Sem adubo & $632 \mathrm{a}$ & 31,03 \\
EB & $541 \mathrm{a}$ & 31,03 \\
CF & $613 \mathrm{a}$ & 31,03 \\
CF+EB & $560 \mathrm{a}$ & 31,03 \\
\hline
\end{tabular}

EPM: erro padrão da média. Médias seguidas da mesma letra minúscula na coluna não diferem entre si $(P>0,005)$ pelo teste de Tukey. DPP: densidade populacional de perfilhos, EPM: erro padrão da média. EB: esterco de bovinos confinados; CF: cama de frango.

Para Silva, Simioni e Lucena (2013) a adubação orgânica é adicionada como uma base fundamental para as gramíneas, proporcionando maiores índices de produtividade, sendo dificilmente substituída pela adubação inorgânica, sendo que, pode ser uma alternativa sustentável e de menor custo para a produção.

Nos estudos de Orrico Junior et al. (2013),foi encontrado resultados diferentes do presente trabalho. Utilizaram biofertilizante de suínos na adubação do capim Piatã, onde proporcionou o melhor desempenho da planta, sendo que a produção de massa de forragem foi semelhante ou superior aos resultados com adubação mineral. Os autores afirmam que os compostos oriundos de camas de frango, desde que utilizados de maneira padronizada (corrigindo a dose de acordo com o teor de $\mathrm{N}$ de cada composto), não apresentam diferenças no aproveitamento dos nutrientes, proporcionando assim um crescimento similar entre as plantas avaliadas no experimento.

No presente trabalho, o clima pode ter influenciado, uma vez que as chuvas regularizaram no mês de março, momento em que estava encerrando as avaliações, e provavelmente a falta de chuva tenha prejudicado na mineralização da cama de frango e esterco de confinamento. Por outro lado, de acordo com a análise de solo a saturação por base já estava muito alta (54,1\%), e também pode ter contribuído para a não variação significativa entre os adubos e a testemunha. Diferentemente do que encontraram Portugal et al., (2009) com o uso de cama de frango relatam que com a adubação os valores de $P$ aumentaram de uma forma significativa em até 3,4 vezes. Houve aumento no $\mathrm{pH}$ do solo, o que proporcionou aumento no magnésio, cálcio e saturação por bases. Também houve aumento na capacidade de troca catiônica, sendo assim, melhorando a fertilidade do solo e consequentemente a melhoria da produção da pastagem. Para Teles (2013) a cama de frango é um resíduo de grande valor agronômico, pois tem em sua composição grandes teores de N, P e Ca, sem contar com os outros minerais existentes nesse resíduo. A liberação ou mineralização dessa cama no solo é de $50 \%$ do $\mathrm{N}$, $60 \%$ do $P$ e $100 \%$ do $K$. Já no trabalho de Fagundes et al., (2005) a densidade populacional de perfilhos do capim-braquiária variou conforme a estação do ano. Onde foi observado que a densidade populacional de perfilhos, atingiu valores mais baixos no inverno. Este comportamento pode ser explicado pelas condições desfavoráveis de crescimento, como disponibilidade limitada de água, luz e temperatura típica daquela estação do ano e apresentou maiores números de perfilhos no verão.

Para Orrico Junior et al. (2013) existe uma relação direta da taxa de aparecimento foliar com a densidade populacional de perfilhos, 0 que determina o potencial de perfilhamento de dado genótipo, pois cada folha formada representa potencialmente o surgimento de um novo perfilho, ou seja, a geração de novas gemas axilares.

De acordo com as análises, para o intervalo de cortes, não houve diferença entre as cultivares (Tabela 4).

Tabela 4. Intervalo de corte em parcelas de capins Marandu e Piatã, submetidos à adubação com cama de frango e esterco de bovinos confinados.
EPM 


\begin{tabular}{ccc}
\hline \multicolumn{3}{c}{ corte (dias) } \\
\hline Marandu & $16,98 \mathrm{a}$ & 0,40 \\
Piatã & $16,58 \mathrm{a}$ & 0,40 \\
\hline
\end{tabular}

EPM: erro padrão da média. Médias seguidas da mesma letra minúscula na coluna não diferem entre si $(P>0,005)$ pelo teste de Tukey.

As avaliações foram realizadas no processo inicial de formação das pastagens. Desta forma, mesmo havendo diferença entre as cultivares na densidade populacional de perfilhos, o intervalo de rebrota foi o mesmo. Provavelmente com o passar do tempo, as plantas irão adequando suas estruturas e as alturas de corte passariam a determinar variações no intervalo de corte. O clima também pode ter influenciado, uma vez que no mês de janeiro houve pouca chuva, estendo sua normalidade a partir de fevereiro e março, momento em que o experimento estava sendo finalizado. Nos estudos de Edvan et al. (2010), houve diferença para o perfilhamento e para taxa de aparecimento de folhas nas diferentes épocas de corte no experimento realizado com adubação de esterco bovino e digesta bovina no capim- Buffel, onde no terceiro corte observou-se o maior número de perfilhos e mais elevada taxa de aparecimento de folhas. Esse fato se deve principalmente aos efeitos climáticos da região, observados no período de realização do experimento. Segundo estudo feito por Gomide (1997), o perfilhamento da forrageira é favorecido sob condições de alta intensidade luminosa e temperaturas não elevadas favorecem o acúmulo de fotoassimilados nas plantas.

Para as adubações houve efeito sobre o intervalo de corte (Tabela 5).

Tabela 5. Intervalo de corte em parcelas de capins Marandu e Piatã, submetidos à adubação com cama de frango e esterco de bovinos confinados.

\begin{tabular}{ccc}
\hline Adubo & $\begin{array}{c}\text { Intervalo de } \\
\text { corte(dias) }\end{array}$ & EPM \\
\hline Sem adubo & $17,10 \mathrm{a}$ & 0,56 \\
EB & $18,35 \mathrm{a}$ & 0,56 \\
CF & $15,88 \mathrm{ab}$ & 0,56 \\
CF+EB & $15,81 \mathrm{ab}$ & 0,56 \\
\hline
\end{tabular}

EPM: erro padrão da média. Médias seguidas da mesma letra minúscula na coluna não diferem entre si $(P>0,005)$ pelo teste de Tukey. DPP: densidade populacional de perfilhos, EPM: erro padrão da média. EB: esterco de bovinos confinados; CF: cama de frango.

A utilização da cama de frango apresentou variação no intervalo de corte, visto que, a cama de frango separada, e a cama de frango misturada com o esterco de baia, proporcionou melhores resultados estatísticos comparados aos tratamentos testemunhas e com adubações somente de esterco de confinamento. Segundo o trabalho de Silva, Simioni e Lucena (2013), utilizando diferentes adubos (esterco de frango, esterco bovino, compostagem, NPK e a testemunha), constataram que o esterco de frango proporcionou melhores resultados quando comparado aos demais tratamentos tanto no período das águas quanto no da seca. De acordo com Sartor (2009), grande parte dos efeitos positivos do $\mathrm{N}$ sobre a produção de forragem pode ser explicado pela ação direta desse elemento sobre o processo fotossintético, onde a dependência da nutrição nitrogenada ao processo de fotossíntese reflete na participação do $\mathrm{N}$ na estrutura da clorofila, na cadeia de transporte de elétrons da fotossíntese e de todas as enzimas envolvidas no metabolismo do carbono.

De acordo com as análises de números de corte (Tabela 6), não houve diferença para os cultivares.

Tabela 6. Número de cortes em parcelas de capins Marandu e Piatã, submetidos à adubação com cama de frango e esterco de bovinos confinados.

\begin{tabular}{ccc}
\hline Cultivar & $\begin{array}{c}\text { Numero de corte } \\
\text { (dias) }\end{array}$ & EPM \\
\hline Marandu & $3,56 \mathrm{a}$ & 0,14 \\
Piatã & $3,38 \mathrm{a}$ & 0,14 \\
\hline
\end{tabular}

EPM: erro padrão da média.

No estudo de Alexandrino (2000) os cortes mais frequentes interferiram negativamente no número de perfilhos da Brachiaria brizantha cv. Marandu. A Densidade Populacional nas plantas desfolhadas com maior frequência foi $18,74 \%$, o que foi inferior àquelas desfolhadas menos frequentemente. Já nos estudos de Sbrissia (2000), para evitar o complexo de auto-desbaste, para que a forrageira tenha uma boa relação com densidade populacional de perfilhos e tamanho de perfilhos, é necessário manejar a altura do pastejo (corte) e a pressão colocada sobre a pastagem. De acordo com a análise de números de corte (Tabela 7) experimento, não houve diferença para as adubações.

Tabela 7. Número de cortes em parcelas de capim Marandu e Piatã, submetidos à adubação com cama de frango e esterco de bovinos confinados.

\begin{tabular}{ccc}
\hline Adubo & $\begin{array}{c}\text { Número de } \\
\text { cortes(dia) }\end{array}$ & EPM \\
\hline Sem adubo & $3,50 \mathrm{a}$ & 0,20 \\
EB & $3,13 \mathrm{a}$ & 0,20 \\
CF & $3,63 \mathrm{a}$ & 0,20 \\
CF+EB & $3,63 \mathrm{a}$ & 0,20
\end{tabular}

EPM: erro padrão da média.

Os números de cortes não se diferiram para os cultivares, como também não se diferiram em relação às adubações.

\section{Considerações finais}

As cultivares de Brachiaria brizantha Marandu e Piatã apresentaram variação na densidade populacional de perfilhos.

A adubação com cama de frango e esterco de baia de confinamento apresentou efeito sobre o intervalo de corte.

Recomenda-se a adubação com cama de frango sobre pastagens de Marandu e Piatã para proporcionar a diminuição do intervalo de pastejo.

\section{Referências}

ALEXANDRINO, E. Crescimento e características químicas e morfogênicas da Brachiaria brizantha cv. 
Marandu submetida a cortes e diferentes doses de nitrogênio. 2000. 132 f. (Dissertação de Mestrado) Universidade Federal de Viçosa, Viçosa, 2000.

AZEVEDO-JUNIOR, N. P. Produção e composição bromatológica do capim-Piatã em diferentes frequências de corte sob irrigação. 2011. 72 f. Dissertação (Mestrado) - Curso de Zootecnia, Universidade Federal da Grande Dourados Faculdade de Ciências Agrárias Programa de Pósgraduação em Zootecnia- UFGD, Dourados-MS, 2011.

BARTHRAM, G. T. Experimental techniques: the HFRO sward stick. Aberdeen: Hill

Farming Research Organization/Biennial Report, 1985. p.29-30.

EDVAN, R.L.; SANTOS, E.M.; VASCONCELOS, W.A.; et al. Utilização de adubação orgânica em pastagem de capim-Buffel. Archivos de Zootecnia, Campina Grande-PB, v. 59, n. 228, p.499-508, set. 2010.

Jaílson Lara Fagundes; Sila Carneiro da Silva; Carlos Guilherme Silveira Pedreira; André Fischer Sbrissia; Roberta Aparecida Carnevalli; Carlos Augusto Brandão de Carvalho; Luis Felipe de Moura Pinto. Índice de área foliar, interceptação luminosa e acúmulo de forragem em pastagens de Cynodon spp. sob diferentes intensidades de pastejo. Scientia Agricola, São Paulo. v.56, n.4, p.1141-1150, 1999.

Jailson Lara Fagundes, Dilermando Miranda da Fonseca, Claudio Mistura, Rodrigo Vieirade Morais,Claudio Manoel Teixeira Vitor, Gilbertoda Cunha Reis, Daniel Rume Casagrande, Manoel Eduardo Rozalino Santos. Índice de Areá Foliar, densidade de perfilhos e acúmulo de forragem em pastagem de Capim- Baquiária adubada com nitrogênio. B. Indústr.anim., Nova OdessaSP,v.62,n.2, p.125-133, jun. 2005.

FIALHO, C.A.; SILVA, S.C.; GIMENES, F.M.A.; et al. Tiller population density and tillering dynamics in marandu palisade grass subjected to strategies of rotational stocking management and nitrogen fertilization. Acta Scientiarum. Animal Sciences, Maringá, v. 34, n. 3, p. 245-251, July-Sept., 2012.

GOMIDE, J. A. Morfogênese e Análise de Crescimento de Gramíneas Tropicais. In: Simpósio Internacional sobre Produção Animal em Pastejo. p. 411-430, 1997.

INMET. INMET-Instituto

Nacional de Meterologia: Estações convencionais gráficos. 2015.

MANSO, K. R. J.; FERREIRA, O. M. Confinamento de bovinos: estudo do gerenciamento dos resíduos. 2007. 19 f. TCC (Graduação) - Curso de Engenharia Ambiental, Departamento de
Engenharia, Universidade Católica de Goiás, Goiânia - GO, 2007.

Marco Antonio Previdelli Orrico Juniorl; Stanley Ribeiro Centurion; Ana Carolina Amorim Orrico; Arley Borges de Morais Oliveira, Natália da Silva Sunada. Características produtivas, morfogênicas e estruturais do capim Piatã submetidos a adubação orgânica. Ciência Rural, Santa Maria-RS, v. 43, n. 7, p.1238-1244, jun. 2013. Bimestral.

Edson Marcos Viana Porto, Cláudio Manoel Teixeira Vitor, Dorismar David Alves, Daniel Roger de Oliveira, Marcos Rodrigues Doroteu, Valdeir Dias Gonçalves. Densidade populacional de perfilhos de cultivares de brachiaria brizantha submetidos à adubação nitrogenada. Acsa - Agropecuária Científica no Semiárido, Campus de Patos - PB, v. 10, n. 4, p.46-51, dez. 2014.

PORTUGAL A. F; RIBEIRO, D. O.; CARBALLAL, M. R.;et AL. Efeitos do uso de cama de frango, associada a diferentes doses de nitrogênio no acúmulo de matéria seca em Brachiaria brizantha cv. Marandu. In: II Simpósio Internacional sobre Gerenciamento de Resíduos de Animais Uso dos Resíduos da Produção Animal como Fertilizante, 1.Florianópolis-SC. Anais... FlorianópolisSP:SIGERA, 2009.p.296.

RODRIGUES, D. de C. Produção de Forragem de cultivares de Brachiaria brizhanta (Hochst ex A. Rich) Stapk e modelagem de respostas produtivas em função de variáveis climáticas. 2014. $94 \mathrm{f}$. Dissertação (Mestrado) - Curso de Agronomia, Escola Superior de Agricultura Luiz de Queiroz, Universidade de São Paulo, Piracicaba-SP, 2014.

SANTOS, G. T. Dinâmica e compensação tamanho/densidade populacional de perfilhos em pastos de capim- quicuiu sob lotação intermitente. 2014.104f. Tese (Doutorado em Agronomia - Área: Produção Vegetal). Universidade do Estado de Santa Catarina. Programa de Pós-graduação em Agronomia, Lages-SC, 2014.

SARTOR, L. R. Eficiência de utilização de nitrogênio, fósforo e potássio por plantas de Papuã submetidas a diferentes Intensidades de pastejo e Níveis de Nitrogênio. 2009. 115 f. Dissertação (Mestrado) - Curso de Agronomia, Universidade Tecnológica Federal do Paraná, Pato Branco-RS, 2009. Disponível em: <http://repositorio.utfpr.edu.br/sspui/bitstream/1/255/ 1/PB_PPGA_M_Sartor, Laércio Ricardo_2009.pdf>. Acesso em: 12 nov. 2015.

SBRISSIA, A. F. Compensação tamanho/densidade populacional de perfilhos em pastagens de Cynodon spp. 2000. 80 f. Dissertação (Mestrado) Curso de Engenheiro Agrônomo, Escola Superior de Agricultura Luiz Queiroz, Piracicaba-SP, 2000. 
SBRISSIA, A. F; SILVA, S. C. Compensação tamanho/densidade populacional de perfilhos em pastos de capim-marandu. Revista Brasileira de Zootecnia, Lages- Sc, v. 37, p.35-47, 2008. Bimestral.

SILVA, A. A.; SIMIONI, G. F.; LUCENA, A. Efeito da adubação orgânica no crescimento do capim Brachiaria Brizantha cv. Marandu em Parecis/Rondônia. Enciclopédia Biosfera, Centro Científico Conhecer, Goiânia-GO, v.9, n.16, p.923932, 2013.

TELES, J. D. T. Avaliação de produção de massa seca e composição químico-bromatológica de pastagens fertilizada com cama de frango e dejetos de suínos. 2013. 26 f. TCC (Graduação) - Curso de Zootecnia, Universidade Federal de Goiás, GoiâniaGo, 2013. 